\title{
Guest editorial science transfer: oral health and general health - the links between periodontitis, atherosclerosis, and diabetes
}

\author{
Jepsen, Søren ; Stadlinger, Bernd ; Terheyden, Hendrik ; Sanz, Mariano
}

\begin{abstract}
The transfer of knowledge from research and academic communities to clinical practice presents an enormous challenge. This is particularly true for when attempting to convey the clinical relevance and implications of laboratory-based research. A landmark consensus workshop was staged in Europe (La Granja, Spain, November 2012) jointly by the European Federation of Periodontology (EFP) and the American Academy of Periodontology (AAP). This article is protected by copyright. All rights reserved.
\end{abstract}

DOI: https://doi.org/10.1111/jcpe.12484

Posted at the Zurich Open Repository and Archive, University of Zurich

ZORA URL: https://doi.org/10.5167/uzh-118504

Journal Article

Accepted Version

Originally published at:

Jepsen, Søren; Stadlinger, Bernd; Terheyden, Hendrik; Sanz, Mariano (2016). Guest editorial science transfer: oral health and general health - the links between periodontitis, atherosclerosis, and diabetes. Journal of Clinical Periodontology, 42(12):1071-1073.

DOI: https://doi.org/10.1111/jcpe.12484 
Received Date : 23-Nov-2015

Accepted Date : 25-Nov-2015

Article type : Other

\title{
Guest Editorial Science transfer: Oral Health and General Health - the Links between Periodontitis, Atherosclerosis, and Diabetes
}

\author{
Søren Jepsen ${ }^{1}$, Bernd Stadlinger ${ }^{2}$, Hendrik Terheyden ${ }^{3}$, Mariano Sanz ${ }^{4}$ \\ ${ }^{1}$ Dept. of Periodontology, Operative and Preventive Dentistry, University of Bonn, Germany \\ ${ }^{2}$ Clinic of Cranio-Maxillofacial and Oral Surgery, University of Zurich, University Hospital \\ Zurich, Switzerland \\ ${ }^{3}$ Dept. of Oral \& Maxillofacial Surgery, Red Cross Hospital, Kassel, Germany \\ ${ }^{4}$ Dept. of Periodontology, Faculty of Odontology, University Complutense, Madrid, Spain
}

Short running title: Science transfer: oral and general health

Keywords: Periodontitis, Atherosclerosis, Diabetes, Bacteremia

\section{Conflict of interest and Source of Funding:}

The authors do not declare any conflict of interest with regard to the promotion of the scientific content of the joint EFP/AAP workshop on "Periodontal and Systemic Diseases" by this project. Funds for the production of the educational film and its dissemination were provided by educational grants from Quintessence and Sunstar.

This article has been accepted for publication and undergone full peer review but has not been through the copyediting, typesetting, pagination and proofreading process, which may lead to differences between this version and the Version of Record. Please cite this article as doi: $10.1111 /$ jcpe. 12484

This article is protected by copyright. All rights reserved. 


\section{Corresponding author:}

Søren Jepsen

Dept. of Periodontology, Operative and Preventive Dentistry,

University of Bonn

Welschnonnenstrasse 17

53111 Bonn, Germany

Phone: +4922828722480

Fax: +4922828722161

E-mail: jepsen@uni-bonn.de

The transfer of knowledge from research and academic communities to clinical practice presents an enormous challenge. This is particularly true for when attempting to convey the clinical relevance and implications of laboratory-based research.

A landmark consensus workshop was staged in Europe (La Granja, Spain, November 2012) jointly by the European Federation of Periodontology (EFP) and the American Academy of Periodontology (AAP). The subject was "Periodontal and Systemic Diseases" and the proceedings were published in a supplementary issue of the Journal of Clinical Periodontology which is freely available online (at http://onlinelibrary.wiley.com/doi/10.1111/jcpe.2013.40.issue-s14/issuetoc).

Apart from systematically reviewing the scientific literature on epidemiological associations and clinical intervention studies, special attention was paid to the biological mechanisms underpinning the proven epidemiological associations between oral and systemic diseases. Whilst it was recognised that many of the cellular and molecular details remain to be fully characterised, and that our current knowledge is based principally on findings from in vitro

This article is protected by copyright. All rights reserved. 
and experimental animal research, a clear picture has emerged in which systemic inflammation appears to provide the missing link.

A landmark computer animated 3D scientific film has been created to visualize some of the key aspects of the molecular and cellular links between periodontal infection/inflammation and systemic diseases/conditions such as atherosclerosis and type 2 diabetes, based upon the evidence analysed at the consensus conference (Tonetti \& van Dyke et al. 2013, D’Auito et al. 2013, Reyes et al. 2013, Schenkein \& Loos 2013, Chapple \& Genco et al. 2013, Taylor et al. 2013, Engebretson \& Kocher 2013). The film had its world premiere at the recent EuroPerio 8 conference in London and will now be made available on the EFP website (www.efp.org). Both, an expert as well as a public version of the film have been prepared, and it is hoped that it will serve multiple purposes, such as the education of health professionals, patients and the general public on the systemic consequences of periodontal disease. It will also serve as the backbone of the upcoming EFP awareness campaign "periodontal health for a better life".

The film opens with an animated portrayal of periodontitis and its pathological processes within the periodontal pocket, where there is close interaction between the bacteria residing within the subgingival biofilm on the root surface and the ulcerated pocket epithelium. A storyboard was developed that described the following sequence of events:

1) Dissemination of periodontal bacteria into the circulation, thereby eliciting systemic inflammation that leads to;

2) Promotion of atherosclerosis;

3) Impaired glycemic control, with negative effects on the periodontium and

4) The potential benefits of periodontal treatment.

This article is protected by copyright. All rights reserved. 
Periodontal bacteria from the biofilm at the interface with the ulcerated periodontal pocket epithelium enter the circulation during speech, eating and tooth brushing and disseminate throughout the body via the blood circulation (Tomás et al. 2012) (Figure 1).

There is evidence that periodontal bacteria can invade the endothelial lining cells of blood vessels (in vitro), can induce atherosclerosis in animal models of disease, and also that the host's inflammatory-immune response favours atheroma formation, maturation and exacerbation (Reyes et al. 2013, Schenkein \& Loos 2013, Kebschull et al. 2010). Therefore these events were animated to illustrate the different stages of atherosclerosis.

Bacteria within the bloodstream also activate an acute-phase response by the liver and activate immune cells, such as neutrophils, to release oxygen radicals, thereby generating 'oxidative stress' within the circulation, further driving systemic inflammation. As illustrated in the subsequent scene of the film this may in turn lead to reduced $\beta$-cell function, apoptosis and insulin resistance (Figure 2). These conspire to promote impaired glycaemic control and type 2 diabetes. The mechanisms by which diabetes negatively impacts upon the periodontium are illustrated (Taylor et al. 2013, Preshaw et al. 2012, Duarte et al. 2014) with a specific focus on the formation of advanced glycation end-products (AGEs), emphasising the bi-directionality of the relationship between periodontitis and diabetes.

Finally, the potential benefits of periodontal treatment on systemic health are graphically illustrated. A reduction of the oral infectious burden can result in a reduction of the overall inflammatory load, with positive effects demonstrated on surrogate measures of atherosclerosis (D’Aiuto et al. 203, Teeuw et al. 2014) and on glycaemic control, as evidenced by several meta-analyses (Engebretsson \& Kocher 2013, Li et al. 2015).

This article is protected by copyright. All rights reserved. 
In summary, this project has focussed on making the invisible very visible, in order to facilitate a better understanding of biological processes through the power of graphic imagery. The overall goal is to motivate specialists, dental practitioners, as well as dental students using computer animated science films, in order to engage these groups in current biologically relevant topics for their day-today practical activities. Understanding of pathophysiological processes should be greatly facilitated by the movie and this project should be viewed as a contribution to "Science-Transfer", as already takes place in other biomedical disciplines and scientific journals (i.e. http://multimedia.mcb.harvard.edu,

http://www.nature.com/nature/videoarchive/, http://www.nature.com/ni/multimedia/index.html, http://video.sciencemag.org).

With the explosion of scientific knowledge over the last two decades and an ever-increasing number of original scientific publications it has become more and more important to translate current highly relevant research topics in an easy to digest manner for oral health professionals. This approach also facilitates the dialogue with our medical colleagues as well as communication with our patients and the public.

\section{Acknowledgements}

The contributions of the members of the Advisory Board: Prof. Iain Chapple, Prof. Robert Genco, Prof. Evanthia Lalla, Prof. Shinya Murakami as well as the imput of Dr. Moritz Kebschull are highly acknowledged. We thank the production team Dr. Marko Reschke, Matthias Gauer, Thomas Kramer, Jörg Faßbender (iAS - Quintessence) for their excellent work. We are grateful for the support by the project partner Sunstar Foundation (Fumihiro 
Awashima, Dr. Marzia Massignani,) and the expert management of Änne Klebba (Quintessence Publishing) and in particular to Dr. Alexander Ammann (Quintessence Publishing) for his vision.

\section{References}

Chapple, I.L.C., Genco, R., and on behalf of working group 2 of the joint EFP/AAP workshop. (2013) Diabetes and periodontal diseases: consensus report of the Joint EFP/AAP Workshop on Periodontitis and Systemic Diseases. Journal of Clinical Periodontology 2013; 40 (Suppl. 14): 106-112.

D’Aiuto, F., Orlandi, M. \& Gunsolley, J. C. (2013) Evidence that periodontal treatment improves biomarkers and ACVD outcomes. Journal of Clinical Periodontology 40 (Suppl14), 85-105.

Duarte, P.M., Bezerra, J.P., Miranda, T.S., Feres, M., Chambrone, L., Shaddox, L.M. (2014) Local levels of inflammatory mediators in uncontrolled type 2 diabetic subjects with chronic periodontitis. Journal of Clinical Periodontology 41:11-18.

Engebretson, S. \& Kocher, T. (2013) Evidence that periodontal treatment improves diabetes outcomes: a Systematic Review and Meta-analysis. Journal of Clinical Periodontology 40 (Suppl 14), 153-163.

Kebschull, M., Demmer, R.T., Papapanou, P.N. (2010) "Gum bug, leave my heart alone!"-epidemiologic and mechanistic evidence linking periodontal infections and atherosclerosis. Journal of Dental Research 89: 879-902.

This article is protected by copyright. All rights reserved. 
Li, Q., Hao, S., Fang, J., Xie, J., Kong, X.-H., Yang, J.-X. (2015)

Effect of non-surgical periodontal treatment on glycemic control of patients with diabetes: a meta-analysis of randomized controlled trials. Trials 16: 291-

Preshaw, P.M., Alba, A.L., Herrera, D., Jepsen, S, Konstantinidis, A., Makrilakis, K., Taylor R. (2012) Periodontitis and diabetes: a two-way relationship. Diabetologia 55: 21-31.

Reyes, L., Kozarov, E., Herrera, D., Roldan, S. \& Progulske-Fox, A. (2013). Periodontal bacterial invasion and infection: Contribution to cardiovascular disease. Journal of Clinical Periodontology 40 (Suppl 14), 30-50.

Schenkein, H. A. \& Loos, B. G. (2013) Inflammatory mechanisms linking periodontal diseases to cardiovascular diseases. Journal of Clinical Periodontology 40 (Suppl 14), 51-69.

Taylor, J. J., Preshaw, P. M. \& Lalla, E. (2013) A review of the evidence for pathogenic mechanisms that may link periodontitis and diabetes.

Journal of Clinical Periodontology 40 (Suppl 14), 113-134.

Teeuw ,W.J., Slot D.E., Susanto, H., Gerdes, V.E., Abbas, F., D'Aiuto, F., et al. (2014) Treatment of periodontitis improves the atherosclerotic profile: a systematic review and meta-analysis. Journal of Clinical Periodontology 41: 70-79.

Tomás, I., Diz, P., Tobías, A., Scully, C., Donos, N. (2012) Periodontal health status and bacteraemia from daily oral activities: systematic review/meta-analysis. Journal of Clinical

This article is protected by copyright. All rights reserved. 
Periodontology 39: 213-228.

Tonetti, M.S., Van Dyke,T.E. and on behalf of working group 1 of the joint EFP/ AAP workshop. (2013) Periodontitis and atherosclerotic cardiovascular disease: consensus report of the Joint EFP/AAP Workshop on Periodontitis and Systemic Diseases. Journal of Clinical Periodontology 40 (Suppl 14): 24-29.

\section{Figure Legends:}

Figure 1: Periodontal bacteria from the biofilm repeatedly enter the blood vessels of the gingiva through the ulcerated pocket epithelium. Similarly, locally produced inflammatory mediators will shed into the bloodstream.

Figure 2: Membrane-bound insulin receptors register the presence of insulin in the blood.

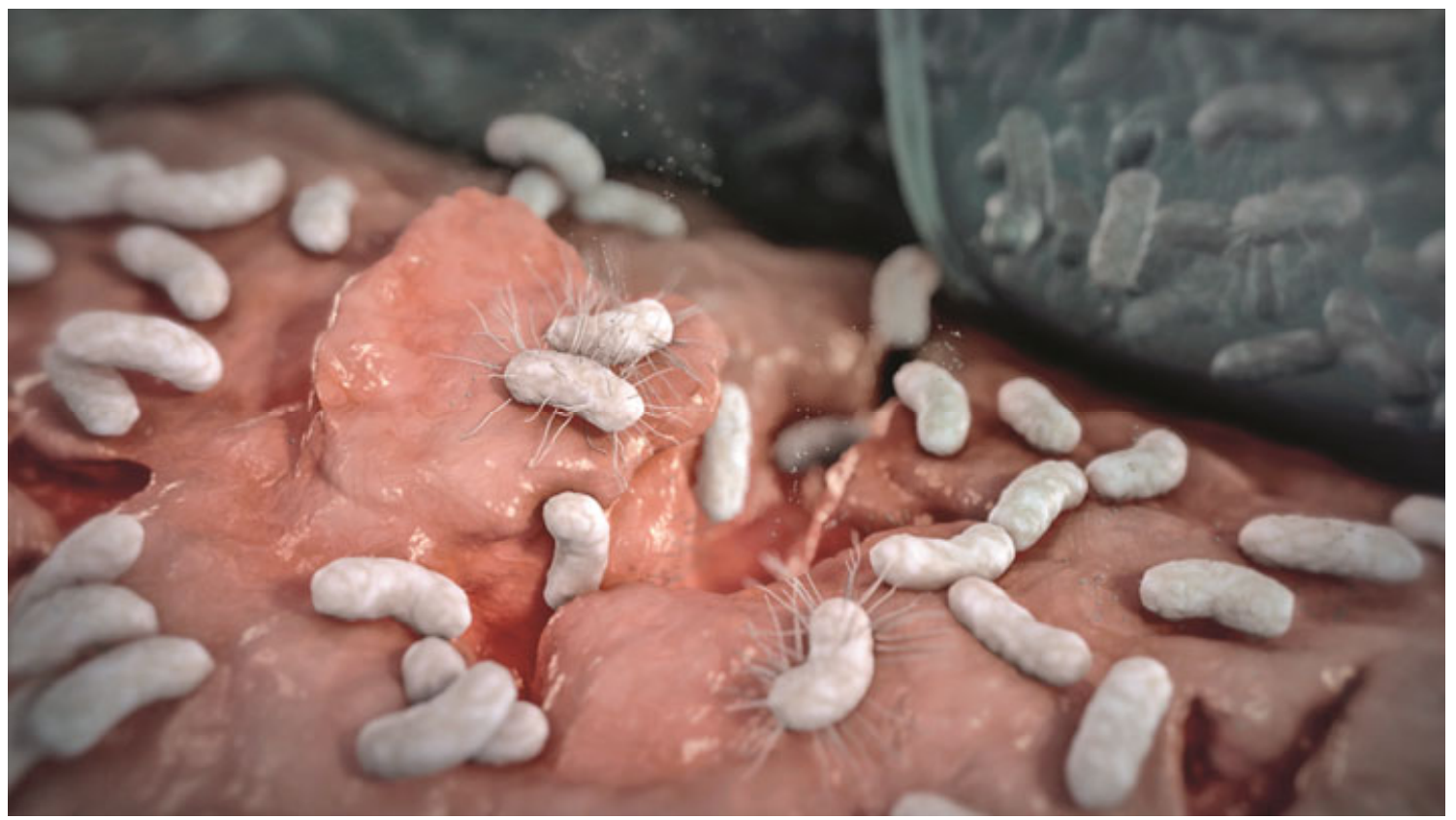

This article is protected by copyright. All rights reserved. 

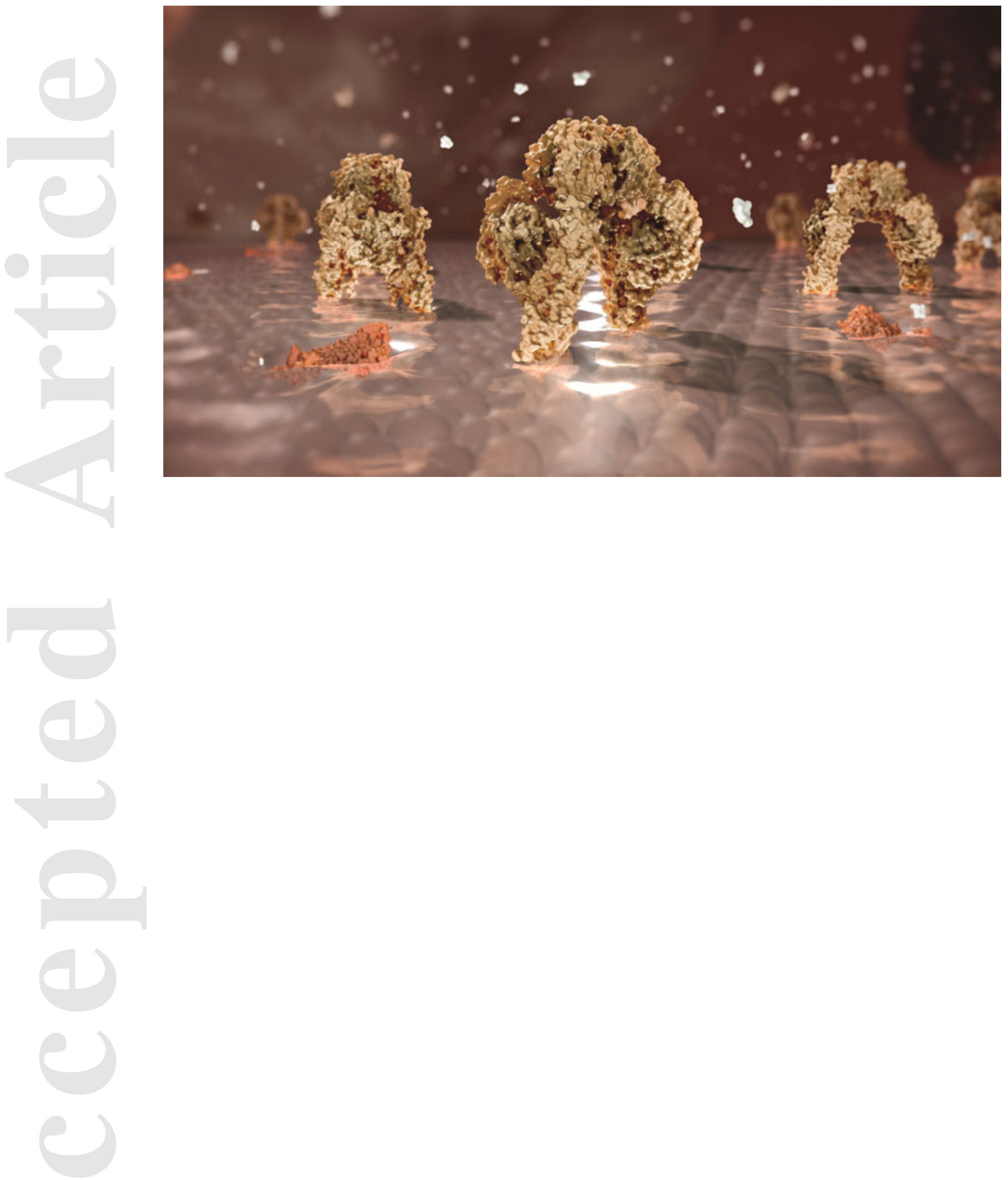

This article is protected by copyright. All rights reserved. 